\title{
Optimizing Jerky Drying Time with Minimal Product Impact
}

\author{
Timothy J. Bowser*, R. Scott Frazier, Paul R. Weckler and Stacey J. Kowalski
}

Department of Biosystems and Agricultural Engineering, Oklahoma State University, Stillwater, Oklahoma, USA

\begin{abstract}
Jerky products are a popular snack in today's society. The process of making jerky products is very time consuming -especially the dehydration process. If the process is sped up the producer will save time and money. This study focuses mainly on speeding up dehydration time with minimal potential impact on the final product. Beef jerky was our test product and was made from eye of round sliced to $5 \mathrm{~mm}$, vacuum packaged and frozen to $-10 \mathrm{C}$. The product was marinated in a jerky seasoning for 1 hour. A two level factorial array experiment was designed to identify the optimum levels of four control factors that could affect dehydration time: $\mathrm{pH}$, freeze/thaw, product orientation, and tenderization. Half of the packages were thawed at $5 \mathrm{C}$ and then refrozen to account for two levels of freeze-thaw cycles. The two $\mathrm{pH}$ levels were "unadjusted" and "adjusted". White vinegar was added to the marinade to adjust the pH to within 5 to 5.25 . Half of the jerky samples were tenderized by adding $0.5 \mathrm{mg}$ of a commercial liquid papain preparation to the marinade. The meat was pasteurized under a wet bulb temperature of $60 \mathrm{C}$ for $12 \mathrm{~min}$ and dried for 5 hours at $65 \mathrm{C}$ dry bulb. Treatments were repeated in triplicate. Tenderizer had the greatest effect on reducing the dehydration time, followed by adjusted $\mathrm{pH}$ and vertical orientation. Dehydration times for all experiments averaged 258 min and ranged from 146 to 386 min. A response optimization model predicted (95\% confidence level) a dehydration time of $178 \mathrm{~min}$.
\end{abstract}

Keywords: Jerky, drying time, optimization, $\mathrm{pH}$, orientation.

\section{INTRODUCTION}

Dried meat is one of the oldest preserved foods known to mankind. Before recorded history, warriors and travelers traversing the trade routes along the Mediterranean Sea purchased or traded for jerky products [1] that were nutritious and convenient. Continuous improvement over the years has resulted in safer, more appealing dehydrated meats [2]. Jerky products have steadily increased in popularity -today an estimated 39\% of all American families regularly purchase meat snacks [3]. Following tradition, the U.S. Army's most recent combat food, the "First Strike Ration" contains beef jerky [4].

Jerky manufacturing is a time consuming process because meat must be dried slowly at a relatively low temperature. Bowser [5] describes a 6 hour processing cycle for a low-cost batch dehydrator that was developed for small-scale processors. Dehydration time varies depending on process variables such as dehydrator temperature setting, lethality process, air circulation, ambient relative humidity, heat energy available and jerky slice thickness. Processors may be able to reduce production costs and increase product throughput by reducing dehydration times. The objective of this study is to identify factors that could potentially reduce dehydration time without drastically affecting the final product. The factors must be easy to implement -allowing virtually any processor to adopt one or more of the factors in their manufacturing process. Four factors that could potentially be used to reduce dehydration time were identified and tested in this study:

*Address correspondence to this author at the Department of Biosystems and Agricultural Engineering, Oklahoma State University, Stillwater, Oklahoma, USA; Tel: 405-744-6313; Fax: 405-744-6688;

E-mail: bowser@okstate.edu
1. $\mathrm{pH}$

2. Product orientation

3. Freeze-thaw cycling

4. Chemical tenderization

Thiagarajan et al. [6] observed that a change in product $\mathrm{pH}$ reduced the dehydration time required for jerky processing. This observation followed from the well known fact that meat products hold the least amount of moisture at their isoelectric point which corresponds to a $\mathrm{pH}$ value of about $5.2[7]$.

Research [8] suggests that the physical orientation of product in a dehydrator may have a significant effect on dehydration time. Orientation of meat products in a dehydrator mainly depends on the physical properties of the product, the design of the dehydrator and the choice of the operator. Most jerkys are thin-cut meat strips that can be hung by hooks, draped across supports, pierced by and hung on a support or fully supported by a tray or shelf. Available space and air circulation within a given dehydrator may favor a particular product orientation and support structure. For instance, dehydrators with horizontal trays often feature horizontal air flow which promotes improved circulation compared to vertical air flow which would be forced to move around product and trays rather than over them. Operators may select different product orientations to provide convenience and speed in processing or to achieve certain finished product characteristics.

Restructured jerky products do not permit handling prior to dehydration and must be fully supported by trays. Only portions of this study could be applied to restructured meat jerkys. In the case of whole-muscle products, reorientation of the jerky is often possible with equipment changes as de- 
scribed above. For these reasons this study was conducted on whole-muscle products.

The freeze-thaw cycle is known to reduce moisture levels in meats and results in a decreased water holding capacity after thawing [9]. We hypothesized that a repetitive freezethaw cycle applied to raw jerky meat would displace water and subsequently reduce drying time.

Finally, proteolytic enzymes such as bromelain and papain are commonly used for meat tenderization [10]. We theorized that the tenderization process might also reduce the dehydration time by breaking down proteins which could result in freer paths for water movement.

A resolution IV, two-treatment level, factorial experimental design was selected to examine the effect of the four main factors on the rate of dehydration of beef jerky. Factors were considered at two levels each. Resolution IV includes confounding of factors and 3-factor interactions [11]. We believed that this level of resolution was acceptable, because of our preliminary dehydration work with jerky products and our personal assessment of the low likelihood of 3-factor interactions between the unique factors.

\section{MATERIALS AND METHODS}

A small-scale, low-cost dehydrator with a raw product capacity of $130 \mathrm{~kg}$ [5] was selected for jerky processing. Temperature variations within the dehydrator were known to be minimal and air flow was uniform [12]. The dehydrator was outfitted with two live weigh pans to measure product moisture loss during the dehydration process. The weigh pans were $62 \times 41 \mathrm{~cm}$ stainless steel mesh grills. The mesh was $3.2 \mathrm{~mm}$ in diameter, spaced $1.3 \mathrm{~cm}$ on center. The weigh pans were each suspended by a Kevlar thread (strand size 346, \#8800K43, McMaster-Carr, Santa Fe Springs, CA) which was passed through a $3.2 \mathrm{~mm}$ hole in the ceiling of the dehydrator as shown in Fig. (1). A digital force gage (FGV$5 X Y, 2 \mathrm{~kg}$, Shimpo Corp. Instrument Division, Kyoto, Japan) was mounted outside of the dehydrator and attached to

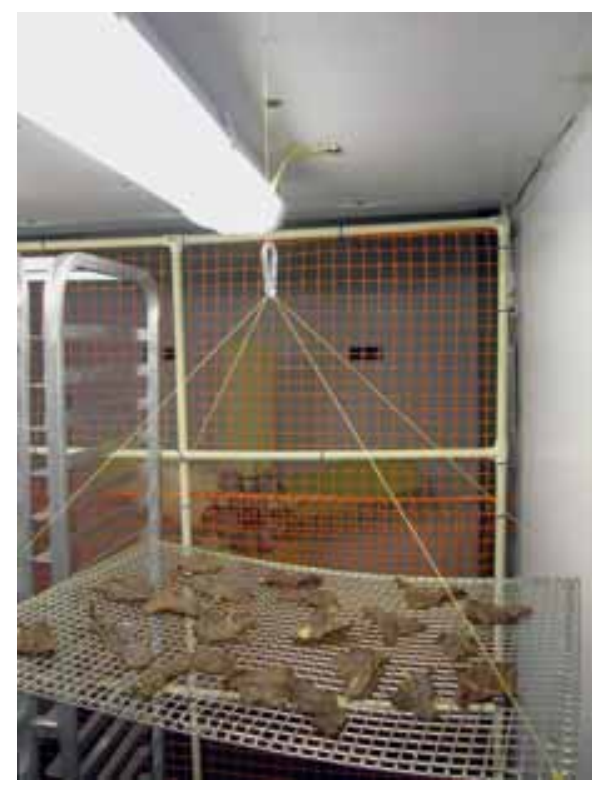

Fig. (1). Weigh pan setup in dehydrator for continuously monitoring weight loss of product. the free end of the Kevlar cord. The Kevlar cord was lubricated with Teflon Multi-use Dry Wax Lubricant (part no. D00110101, Finish line, Inc., Bay Shore, NY) and sheathed with a $3.2 \mathrm{~mm}$ FEP tube (product no. AX100002, Saint Gobain, Mickleton, NJ) for dust protection and to reduce friction. Jerky temperature data was obtained using fine-wire thermocouples (5TC-TT-K-30-72, Omega Engineering, Stamford, CT) that were inserted into the center of the jerky or placed in the air nearby. A Fluke data recorder (Hydra series II model 2635A, Everett, WA) was used to record output from the force gages and thermocouples.

Dehydrator setup and operation procedures followed those outlined by Bowser [1]. The dehydrator internal temperature was set to $65 \mathrm{C}$ and ambient conditions and dehydrator settings were identical for each run. All products were pasteurized using the high humidity, wet-bulb temperature method described in [12] at $60^{\circ} \mathrm{C}$ for $12 \mathrm{~min}$. The dehydration process was considered complete when a moisture removal of $66.7 \%$ of the initial raw product weight was achieved. Moisture removal for each experiment was measured directly using the force gauge and live weigh pan system described above.

The same procedure for product preparation was used in each experiment. Raw beef jerky was cut from an eye of round. Marinade ingredients were $7.5 \mathrm{~g}$ Legg's Old Plantation Jerky Seasoning (blend 131, Calera, AL), 14 g water, $0.55 \mathrm{~g}$ of $6.25 \%$ sodium nitrite, and $1.6 \mathrm{~g}$ liquid smoke. All meat came from the same animal and was sliced and cut to approximately $76.2 \times 76.2 \times 5.08 \mathrm{~mm}$ thick pieces. Slices were vacuum sealed in $76.2 \mu \mathrm{m}$ thick plastic barrier bags (Item 75001942, Prime Source Vacuum Pouches, Packaging Ltd., Spring, TX) and frozen at $-10 \mathrm{C}$ prior to use. Each bag contained about $225 \mathrm{~g}$ of jerky slices that were stacked upon each other.

Marinade ingredients were thoroughly mixed together in a large bowl. Slices of meat were individually coated in the marinade to ensure even distribution. After coating, the pieces were all put back in the bowl together and the bowl was covered with plastic wrap and placed in a cooler at $5 \mathrm{C}$ for 1 hour.

A factorial design of experiment (DOE) with two-level factors and eight treatment conditions was used to determine the effect of control factors on dehydration time [11]. Maximum and minimum levels selected for each factor are shown in Table $\mathbf{1}$.

Table 1. Factors and their Levels Used in the Experimental Design

\begin{tabular}{|l|l|l|}
\hline Variable & High Level (+1) & Low Level (-1) \\
\hline \hline A. Freeze-thaw cycles & 1 cycle & 2 cycles \\
\hline B. Orientation during drying & Horizontal & Vertical \\
\hline C. pH of product & Unadjusted & Adjusted \\
\hline D. Meat tenderization & Included & None \\
\hline
\end{tabular}

Combinations of factor levels were investigated in eight runs that were performed randomly and in triplicate. Freezethaw cycles were accomplished by removing bags of sliced 
jerky from the freezer and tempering them to $5 \mathrm{C}$ over a period of 24 hours, then returning them to the $-10 \mathrm{C}$ freezer.

Horizontal orientation was achieved by laying the jerky slices directly on the weigh pan rack shown in Fig. (1). Wire hooks were used to vertically orient product as shown in Fig. (2). Product $\mathrm{pH}$ was either left unadjusted (as is) or adjusted by adding about $7 \mathrm{ml}$ of white vinegar (Great Value, Bentonville, AR) to the standard marinade recipe to reduce the $\mathrm{pH}$ of the meat to 5.2. Meat tenderization was included (high factor level) or excluded (low factor level) from the process. Tenderization was accomplished by adding $1 \mathrm{mg}$ of tenderizer (Liquipanol T100, Enzyme Development Corp., $\mathrm{NY}$ ) per $454 \mathrm{~g}$ of meat to the marinade. Beef strips were soaked in the marinade for $60 \mathrm{~min}$ at room temperature.

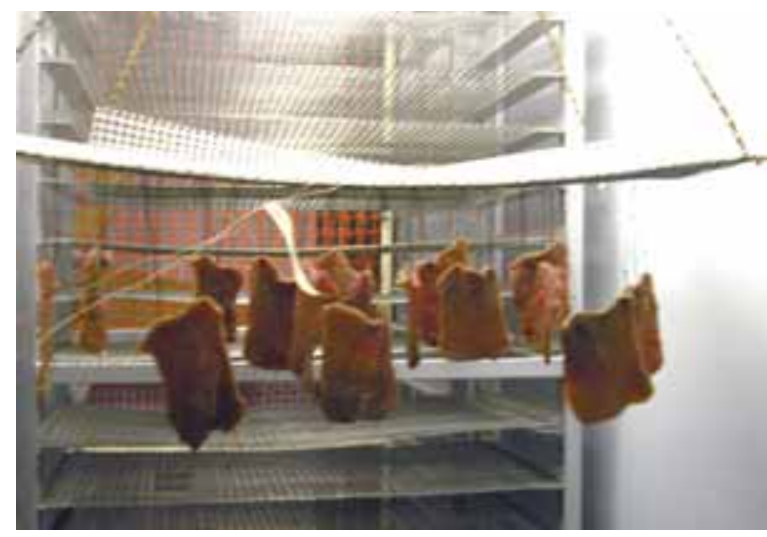

Fig. (2). Vertically oriented product suspended from the weigh pan using wire hooks.

\section{RESULTS}

The eight treatment conditions of the factorial array were tested in the laboratory in triplicate. Dehydration times for all experiments averaged $258 \mathrm{~min}$ and ranged from 146 to 386 min. An analysis of means (ANOM) was completed using MINITAB R14 (Minitab, Inc., State College, PA) to compare the mean value produced by the different levels of each factor as shown in Table $\mathbf{2}$. The last column in Table $\mathbf{2}$ lists the difference between the average of the low and high treatment conditions. The differences observed for the tenderization factor had the greatest magnitude. From ANOM analysis, the "best" factor levels are determined to be (-1) for factor B (vertical orientation), (-1) for factor $\mathrm{C}$ (adjusted $\mathrm{pH}$ ) and (+1) for factor D (tenderizer included).

Table 2. ANOM Table for the Jerky Dehydration Experiment (Minutes)

\begin{tabular}{|l|l|l|l|}
\hline Source & $\mathbf{+ 1}$ Avg. & $\mathbf{- 1}$ Avg. & Diff. \\
\hline \hline A. Freeze-thaw & 259.4 & 256.0 & 3.4 \\
\hline B. Orientation & 278.1 & 237.3 & 40.8 \\
\hline C. $p H$ & 282.4 & 233.0 & 49.4 \\
\hline D. Tenderization & 228.3 & 287.3 & -59.0 \\
\hline
\end{tabular}

A normal probability plot generated by MINITAB is given in Fig. (3). The plot indicates the effects of orientation, $\mathrm{pH}$ and tenderization are significant at $\alpha=0.05$.

\section{Normal Probability Plot of the Standardized Effects}

(response is C9, Alpha $=.05$ )

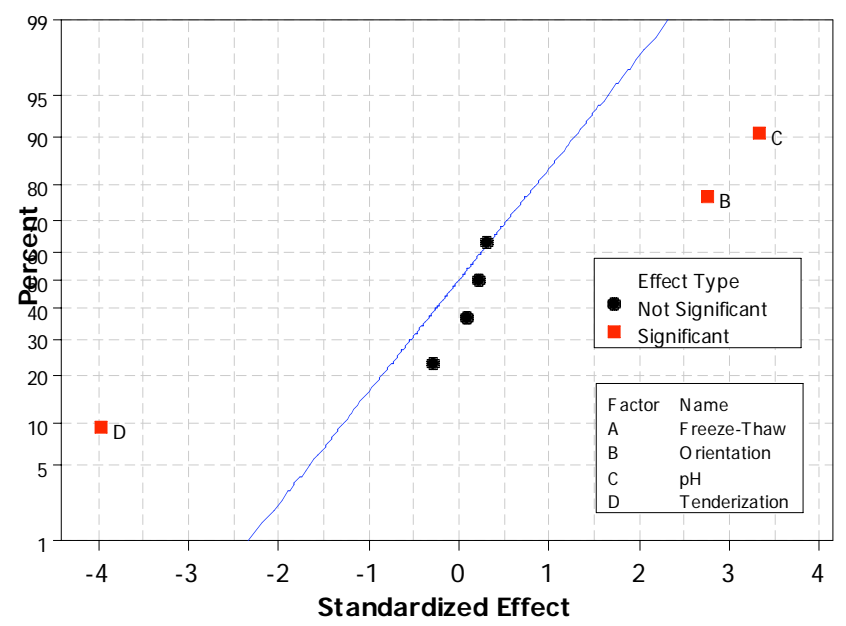

Fig. (3). Normal probability plot of standardized effects $(\alpha=0.05)$.

Estimated effects and coefficients for drying time were computed using MINITAB with results shown in Table 3. Three of the terms, tenderization, $\mathrm{pH}$, and orientation have $\mathrm{p}$ values less than 0.05 , indicating that they have a significant effect on dehydration time. Insignificant terms were removed from the analysis.

Table 3. Estimated Effects and Coefficients for Jerky Dehydration Time from MINITAB Output

\begin{tabular}{|l|l|l|l|l|}
\hline Term & Effect & Coeff & T & P \\
\hline \hline Constant & & 257.1 & 34.73 & 0.000 \\
\hline A. Freeze-thaw & 3.4 & 1.7 & 0.23 & 0.821 \\
\hline B. Orientation & 40.8 & 20.4 & 2.75 & 0.014 \\
\hline C. $\mathrm{pH}$ & 49.4 & 24.7 & 3.33 & 0.004 \\
\hline D. Tenderize & -59.0 & -29.5 & -3.97 & 0.001 \\
\hline AxB & -4.2 & -2.1 & -0.29 & 0.778 \\
\hline AxC & 1.4 & 0.7 & 0.10 & 0.925 \\
\hline AxD & 4.8 & 2.4 & 0.32 & 0.753 \\
\hline
\end{tabular}

An Analysis of Variance (ANOVA) for dehydration time was performed to provide an additional level of analysis. The ANOVA table generated by MINITAB for the jerky dehydration experiment is given in Table 4. Results indicate that the 2-way interactions were insignificant predictors of dehydration time.

Table 4. Analysis of Variance (ANOVA) for Jerky Dehydration Time (Minutes)

\begin{tabular}{|l|l|l|l|l|}
\hline Source & DF & Adj SS & F & P \\
\hline \hline Main effects & 4 & $45,512.5$ & 8.61 & .001 \\
\hline 2-Way interactions & 3 & 255.9 & 0.06 & 0.978 \\
\hline Residual error & 16 & $21,138.7$ & & \\
\hline
\end{tabular}


A response optimization model, a standard calculation available in MINITAB, predicted a dehydration time of 178 min with a $95 \%$ confidence level using the experimental results. A final experimental trial was performed (in duplicate) with the optimized factors (tenderizer, vertical orientation and low $\mathrm{pH}$ ) to confirm results. Dehydration time averaged $261 \mathrm{~min}$ for the optimized trial and $324 \mathrm{~min}$ for the control.

The test product was over-dried since the dehydrator could not be opened to remove the test product without interrupting the dehydration of the control. Over drying of the test product made evaluation of the taste, texture, thickness and appearance of the control impossible.

\section{DISCUSSION}

A DOE approach was used to identify processing parameters that could potentially increase the dehydration rate of beef jerky without significantly changing the final product characteristics. An increase in the dehydration rate of jerky may result in decreased overhead costs of production (including energy) and increased product throughput.

Based on the analysis of experimental results, the most favorable factor levels to reduce dehydration time were tenderization, adjusted $\mathrm{pH}$ and orientation (respectively). Freeze-thaw and factor interactions were less important. The final experimental trial confirmed the conclusion that dehydration process time could be minimized (261 min compared to an average vale for the control of $324 \mathrm{~min}$ ) with product tenderization, vertical orientation and $\mathrm{pH}$ adjustment.

MINITAB predicted an optimized dehydration time of 178 minutes, which was much less than our experimentally measured time of 261 minutes for the optimized process. However, in our tests, the optimized process dried 63 minutes faster than the control, giving a $21.5 \%$ time difference in favor of the optimized process. This indicates that dehydration times may vary due to uncontrolled factors such as environmental and physical properties of the product.

The expected economic impact will vary greatly depending on fixed, and variable costs of the operation, but if the dehydration step is considered to be the sole limiting production factor, the process could achieve a significant decrease in time (or a significant increase in production rate without investment in new equipment). Energy costs per unit of product will also be reduced because the equipment will operate for a shorter period of time for each batch.

Additional research is needed to quantify the effect of the treatments on the final product. Treatment effects will depend a great deal on the cut of meat, slice thickness, marinade, dehydration temperature, equipment configuration, and a host of other process variables that will be unique to the processor. Treatment effects may best be researched by the end user seeking to optimize the dehydration time of a unique jerky process and product.

Review of the drying data revealed a trend during the pasteurization cycle (which was not included in the previous analysis) that possibly affected overall dehydration times. Jerky that was oriented horizontally lost weight more slowly during the pasteurization cycle. This may have been due to an accumulation of condensate on the surface of the meat. Jerky that was dried in the vertical orientation lost weight more quickly during dehydration, probably because the water drained freely from the surface of the jerky. Fig. (4) shows drying curves from two experiments with identical dehydration conditions, except for product orientation and freeze-thaw treatment (the freeze-thaw treatment was shown to have little effect on the dehydration time). The overall pasteurization time was 45 min consisting of a 33 min warmup period with 12 min pasteurization time.

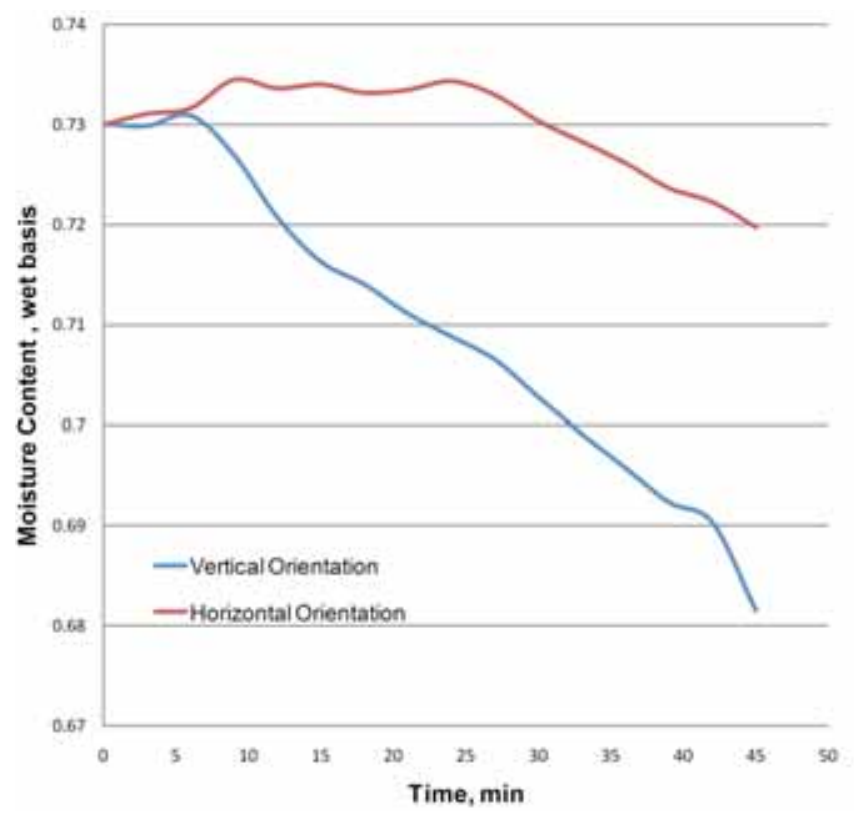

Fig. (4). Moisture content (wet basis) of beef jerky during a $45 \mathrm{~min}$ pasteurization process (product prepared and dehydrated as described in the methods section) with vertical and horizontal orientations and other treatment conditions identical (except for freezethaw).

Jerky pasteurization under high humidity conditions may significantly increase dehydration time when condensate accumulates on the product. Product orientation may not be as significant a factor in decreasing the dehydration time of jerky products if high humidity pasteurization is not part of the manufacturing process. Further study is needed to determine the affects of high humidity pasteurization and dehydration times.

\section{ACKNOWLEDGEMENTS}

The authors acknowledge the following groups at the Oklahoma State University, Stillwater, for their important contributions to this work: The Robert M. Kerr Food \& Agricultural Products Center for providing the facility and funding for the study; and, the Department of Biosystems \& Agricultural Engineering for providing mechanical and electrical support services for the experimental setup.

\section{REFERENCES}

[1] Wentworth EN. Dried meat: early man's travel ration. Agric Hist 1956; 30(1): 2-10.

[2] Baldwin HW. Dried food for fighting men. New York: New York Times 1942; p. SM23.

[3] Market Report, 2004. Foodnavigator.com, USA: Meat Science 2007; vol. 76(20): pp. 253-257.

[4] US Fed News Service, Including US State News. New combat chow options previewed at Pentagon. Washington, D.C 2008. 
[5] Bowser TJ. Construction and operation manual for: low-cost, safe dehydrator for small and very small meat processors. Oklahoma State University, Food and Agricultural Products Center. 2007. [Accessed April 18, 2008]. Internet: http://fapc.okstate.edu/files/ Dehydrator ManualV1.pdf

[6] Thiagarajan IV, Venkatesh M, Satya P. Thin layer drying characteristics of beef jerky. Am Soc Biol Agric Eng Inter Sect Meet 2006; Paper no MBSK 06-214.

[7] Swan JE, Boles JA. Functionality of cow beef in coarse and find ground model systems. J Meat Sci 2006; 72(1): 25-33.

[8] Potter NN, Hotchkiss JH. Food dehydration and concentration. Maryland: Aspen Publishers, Inc. 1998; p. 207.
[9] Rahman MS. Handbook of food preservation. Florida: CRC Press 2007; p.191.

[10] Calkins CR, Sullivan G. Adding enzymes to improve beef tenderness. Beef facts product enhancement, National cattleman's beef association. Centennial Colorado: Cattlemen's Beef Board 2007.

[11] Funkenbusch P. Practical Guide to Designed Experiments; A Unified Modular Approach. New York: Marcel Dekker 2005.

[12] Bowser TJ, Weckler PR. Validation guidelines for a jerky pasteurization process in a low-cost dehydrator. Open Food Sci J 2008; (2): 43-8.

Received: April 10, 2008

Revised: May 22, 2009

Accepted: June 18, 2009

(C) Bowser et al.; Licensee Bentham Open.

This is an open access article licensed under the terms of the Creative Commons Attribution Non-Commercial License (http://creativecommons.org/licenses/by-nc/3.0/) which permits unrestricted, non-commercial use, distribution and reproduction in any medium, provided the work is properly cited. 